\title{
TECNOLOGIA DO PESCADO DE ÁGUA DOCE: APROVEITAMENTO DO PACU (Piaractus mesopotamicus)
}

\author{
E.R. SZENTTAMASY'; S.M.V.B. BARBOSA'; M. OETTERER; I.A.M. MORENO \\ Departamento de Ciencia e Tecnologla Agroindustrial - ESALQ-USP - C.P.9 - CEP:13418-900-Piracicaba,SP
}

\begin{abstract}
RESUMO: Para o estudo da viabilidade do Pacu (Piaractus mesopotamicus) para processamento tecnologico, foram testados os processos de defumaçāo, salga e secagem e enlatamento. Analisou-se tambem a farinha dos resíduos. Utilizou-se peixes provenientes de tanques de piscicultura do municipio de Piracicaba-SP e o produto final foi avaliado para o consumo na merenda escolar municipal. Foram feitas anslises quanto aos teores de lipideos, umidade, proténa e cinza. Os produtos processados por salga, defumação e enlatamento foram analisados também quanto ao teor de sal ( $\mathrm{NaCl}$; os defumados e enlatados foram submetidos a análise sensorial com avaliaçăo de aparência, cor, aroma, sabor e textura. 0 pacu "in natura", defumado, salgado seco e enlatado apresentou, em porcentagem, respectivamente, 18,99; 23,80; 52,53; 18,59 de protefina, 3,79; 2,$69 ; 18,31 ; 14,34$ de lipideos e 1,82; 3,$13 ; 17,76 ; 2,79$ de cinza. Para o pacu enlatado $56 \%$ e $33 \%$ dos degustadores o classificaram como um produto de excelente e bom sabor. $O$ pacu defumado foi classificado como de excelente sabor por $25 \%$ dos provadores e de bom sabor por $55 \%$.
\end{abstract}

Descritores: tecnologia do pescado, processamento do pescado, salga, defumação, enlatamento.

\section{FRESHWATER FISH TECHNOLOGY: UTHLIZATION OF "PACU" (Piaractus mesopotamicus)}

\begin{abstract}
Pacu" (Piaractus mesopotamicus), a freshwater fish, was used with the purpose of studying its quality when smoked, salted and dried, and canned. Waste flour was also analysed. Fish from a fish farm of Piracicaba,SP was used. The intended final use was children's school meal. The results of the analysis of the final products for moisture, protein, lipids, ash and $\mathrm{NaCl}$, in percent, were, respectively, 11.36; $52.53 ; 18.31 ; 17.76 ; 16.25$ for the salted and dried fish; 70.25; $23.80 ; 2.69 ; 3.13 ; 1.17$ for smoked fish; $62.19 ; 18.59 ; 14.34 ; 2.79 ; 1.29$ for canned fish and 15.73; $42.94 ; 20.91 ; 20.42(\mathrm{NaCl}$ not available) for the waste fiour. The smoked and the canned fishes were submitted to taste panels. For the canned product the results were: aspect in the can: $89 \%$ excellent and $11 \%$ good; aspect on plate: $56 \%$ excellent and $44 \%$ good; odor: $67 \%$ excellent and $33 \%$ good; taste: $56 \%$ excellent, $33 \%$ good and $11 \%$ regular and texture: $22 \%$ excellent, $56 \%$ good and $22 \%$ regular (none of the above got the not acceptable note). For the smoked fish the results were, aspect: $45 \%$ excellent and 55\% good; odor: $35 \%$ excellent, $60 \%$ good and $5 \%$ regular; taste: $25 \%$ excellent, $55 \%$ good and $20 \%$ regular and texture: $50 \%$ excellent and $50 \%$ good (none got not acceptable grade).
\end{abstract}

Key Words: fish technology, fish processing, salted and dried fish, smoked fish, canned fish.

\section{INTRODUÇÃO}

Com baixos índices de consumo protéico de pescado "per capita" e infraestrutura pesqueira de armazenagem e processamento precários, o Brasil necessita de viabilização de diversas formas acessíveis e eficientes no que diz respeito ao processamento e conservação do pescado.

Portanto, tendo em vista aumentar o consumo de proteína animal no país e, sabendo-se que o pescado apresenta-se como uma alternativa de baixo custo e de alta qualidade nutricional, torna-se pertinente um estudo das formas de conservação aplicáveis às espécies viáveis existentes no país.

Assim sendo, o pacu apresenta-se como uma boa opção para utilização em processamento, sendo esse o objetivo deste trabalho, já que esta espécie teve poucos estudos a este respeito. Além disso, a Prefeitura Municipal de Piracicaba vem

'Bolsista do CNPq.

Sci. agric., Piracicaba,SP. 50(2):303-310, jum./set. 1993 
criando pacus nas represas de parques públicos.

Estes peixes se destinam à pesca aberta ao público. A presente pesquisa se extende portanto, à comunidade, uma vez que a viabilidade da industrialização do pacu permitirá à Prefeitura a utilização dos peixes nas escolas como parte do programa de merenda escolar.

Foram feitos os processamentos para defumação, salga, enlatamento e aproveitamento dos resíduos para farinha, além das análises sensorial e centesimal desses produtos.

- pacu (Piaractus mesopotamicus) pertence a uma família de cerca de 30 espécies. É encontrado em grande escala na Bacia do Prata e já se tornou uma realidade na piscicultura da América Latina, onde estão sendo criadas grandes quantidades dessa espécie. (BONETTO \& CASTELLO, 1985).

NOMURA (1978) afirma que a alimentação do pacu consiste basicamente de frutos, crustáceos e vegetais. Pode alcançar cerca de $80 \mathrm{~cm}$ de comprimento e $18,5 \mathrm{~kg}$ de peso. Em 1977, o Instituto de Pesca de São Paulo promoveu no Brasil a primeira desova e fecundação induz̧ida para esta espécie.

Segundo FERREIRA \& ANDRADE (1990) a prática de defumar peixes para conserválos é bem antiga, havendo indícios para se fixar a sua origem a dos primeiros homens que se fizeram pescadores.

$\mathrm{Na}$ Inglaterra defuma-se cerca de 400 milhões de peixes pequenos por ano e na Europa alcança-se a cifra de $500 \mathrm{mil}$ toneladas/ano. (CAPONT, 1971).

SegundoHERSON \& HULLAND(1974), a operação de defumação consiste na destilação destrutiva da madeira que pelo calor desprende compostos voláteis. Nestes compostos há substâncias que possuem poder bactericida $e$ portanto conservador como aldeídos, fenóis e ácidos alifáticos. Porém a ação de fungos não é inibida.

Segundo LUDORFF (1963), antes do processo de defumação propriamente dito, a salmouragem terá como objetivo dar mais consistência e sabor ao pescado, desidratando-o parcialmente.

Pode-se usar a defumação a quente e a frio. A frio se utiliza temperatura na faixa de 20 a $25^{\circ} \mathrm{C}$. Na defumação a quente, a ação térmica e a defumação se distinguem. Os peixes depois de convenientemente distribuídos e colocados para defumar, recebem calor que se intensifica lentamente até cerca de $80^{\circ} \mathrm{C}$. O pescado mais úmido se conservará menos que o mais seco. Geralmente, pescado com teor de cerca de $80 \%$ de umidade quando fresco, terá $70 \%$ após a desidratação ocorrida durante a defumação.

Os fatores que devem ser observados para a escolha dos parâmetros de defumação são o tamanho do peixe e a facilidade de penetração da fumaça; sendo que os peixes de couro apresentam maior dificuldade de absorção da fumaça do que os de escamas (ANDRADE \& LIMA, 1983)

BORGSTROM (1961) citou a importância da defumação nas características como aparência, a cor e o aroma que tornam o produto mais atrativo.

O armazenamento dos produtos defumados requer certo cuidado e técnica para a sua boa conservação, segundo LANTZ (i969).

Os produtos obtidos pela defumação a quente não possuem vida de prateleira muito longa, mas podem ser consumidos sem necessidade de cozimento, uma vez que foram cozidos suficientemente durante esse processo (MAGALHÃES, 1961).

SALES et al. (1988) obtiveram um bom produto de tilápia defumada do Nilo (Sarotherodon niloticus) após estocagem a $2{ }^{\circ} \mathrm{C}$ por um periodo de 28 dias.

ANDRADE \& LIMA (1975) lembram que as aplicações de técnicas mais simples de defumação para pescadores, devem ser incentivadas já que são de baixo custo.

A salga é um dos processos mais antigos de preservação de alimentos. A carne do peixe tem sal em torno de 0,08 a $1 \%$, quantidades insuficientes para a conservação; eleva-se esse conteúdo, através de aplicação de cloreto de sódio, a fim de preservar a carne e evitar a sua putrefação (GRECCHI, 1979).

Acreditava-se que o sal atuava como bactericida no processo, já que realmente este tem algumas propriedades antissépticas.

Porém, verifica-se que os próprios cristais de sal podem conter colônias de bactérias que podem se desenvolver assim que tiverem condições adequadas. (MACHADO \& GURGEL, 1965). Assim, FERREIRA \& ANDRADE (1990) recomendam que se pasteurize o sal antes de utilizá-lo.

Segundo LUDORFF (1963) a conservação do produto se dá pela inativação da microflora e enzimas, o que não impede totalmente a deterioração. Certos microorganismos (halófitos) 
conseguem sobreviver a altas concentrações salinas, além disso, podem ocorrer reações devido a contaminantes no sal, e reações enzimáticas, como também a oxidação das gorduras que leva ao aparecimento do ranço oxidativo.

Os métodos de conservação baseados no uso de sal nos tecidos são governados por vários fatores físicos e químicos e, uma série de processos químicos e bioquímicos associados aos vários constituintes do peixe (BORGSTROM, 1961).

HERSON \& HULLAND (1974) afirmam poder retardar ou se desestimular a decomposição por bactérias variando-se o conteúdo de sal do meio. Para a inibição de Clostridium botulinum indicam uma concentração salina mínima de 6,5 a $12 \%$.

BERGER et al. (1968) dividiram os métodos de salga industrial em adição de sal seco, e em salmoura líquida previamente preparada. Nesse último, os peixes, são arrumados em vasilhames e recebem adição de salmoura até completar totalmente os espaços vazios.

A salga por salmoura permite uma armazenagem do produto por 4 a 6 meses a temperatura ambiente. Já a salga a seco diminui esse tempo para 1 ou 2 meses. Convém lembrar que se for utilizado pescado gordo, se faz necessário a armazenagem frigorífica complementar para evitar a oxidação e ranço das gorduras.

MOORJANI et al. (1965) determinaram o valor nutricional da farinha de peixes quanto ao efeito da estocagem nos componentes lipídicos. $O$ desenvolvimento do ranço foi observado em diferentes períodos, e foram determinados $o$ índice de peróxidos e os ácidos graxos livres presentes. Ocorreu elevado índice de oxidação das gorduras (muito rápido) e de peróxidos, que após dois meses de estocagem aumentaram de $6,5 \%$.

Para MEIZIES \& REICHWALD (1973) a defumação em diversas espécies de peixes levou ao aumento da proporção de lipídeos totais, mas não alterou a composição das classes de lipídeos.

SHEVCHENKO \& LAPSHIN (1975) estudaram o efeito de métodos de defumação de filés sobre a resistência dos lipídeos a decomposição oxidativa, verificando que os lipídeos totais aumentaram com o tempo de estocagem. $O$ aumento foi menor nos peixes naturalmente defumados quando comparados com os defumados combinando o processo natural com o de defumação líquida.

A qualidade do peixe defumado é influenciada pela salga, afirma CAPONT (1971), que pode ser forte ou fraca. A salga forte, que se faz com salmoura a $75 \%$ de saturação provoca a formação de uma película constituída das células que absorvem mais cloreto de sódio e que contém aproximadamente $14 \%$ de sal. Segundo o autor, essa película tem grande importância na defumação, pois retém os constituintes fenólicos da fumaça.

$\mathrm{Na}$ superfície foram encontrados 60 $\mathrm{mg} / 100 \mathrm{~g} \mathrm{e}$, logo abaixo dessa faixa o teor cai para $2 \mathrm{mg} / 100 \mathrm{~g}$. O pH da carne do peixe, de 6,7 baixou para 5,8 após a defumação.

Para as determinações da composição química de peixes, é necessário que a amostragem seja feita de modo sistemático, pois a composição varia com a idade, sexo e a estação do ano, além de outros fatores (ANDRADE \& LIMA, 1975).

GEIGER (1962) ainda afirma que o teor de proteína em pescado varia nas diferentes partes do corpo do peixe. Comparada à carne escura, a carne branca contém menor teor de proteína e maior teor de lipídeos.

NATARAJAN \& SREENIVASA (1961) consideram a composição dos peixes dentro das seguintes faixas: umidade de 67,9 a $83,6 \%$; proteína de 13,50 a $19,40 \%$; lipídeos de 0,17 a $10,10 \%$ e cinza de 0,81 a $1,95 \%$. Na análise de peixes inteiros o teor de cinza pode chegar até $5,14 \%$.

FERREIRA \& ANDRADE (1990) determinaram a composição química de várias espécies de água doce, a saber, o mandi (Pimelodus clarias), a carpa (Cyprinus carpio) e a tilápia (Oreochromis niloticus) afim de sugerir os métodos mais adequados de preservação e executar os tipos de processamento estabelecidos com base na composição química de cada espécie.

GEROMEL \& FORSTER (1982) definem como farinha de pescado, produto obtido pela secagem e moagem de peixes, inteiros ou não, e resíduos da indústria de produtos de pescado, visando essencialmente a alimentação animal. E, geralmente um produto sólido obtido através da remoção total ou parcial da água e do óleo do pescado e dos resíduos.

A composição desta se encontra dentro dos seguintes limites: umidade, 6 a $10 \%$; lipídeos, 5 a $12 \%$; proteína, 60 a $75 \%$ e cinza, 10 a $20 \%$.

Segundo BERGER et al. (1968) as farinhas de pescado produzidas para a alimentação animal não podem ser utilizadas na alimentação humana, pois devido ao alto teor de gordura que o produto apresenta, em contato com o ar torna a farinha rançosa e produz sabores inaceitáveis.

A farinha deve ser desengordurada e os fosfatídeos removidos, para que o produto tenha estabilidade. 


\section{MATERIAL E METODOS}

\section{Material}

\section{Peixes}

A matéria prima empregada constituiu-se de pacus provenientes dos reservatórios de piscicultura da Prefeitura do Município de Piracicaba-SP, coletados no mes de janeiro, chegando vivos ao laboratório em tanques com água.

\section{Métodos}

\section{Esquema de trabalho}

Os peixes foram divididos em 3 lotes, conforme o tamanho; os pequenos, de comprimento médio de $20 \mathrm{~cm}$, os médios de comprimento médio de $22 \mathrm{~cm}$ e os grandes de comprimento médio de $24 \mathrm{~cm}$. A separação por tamanho foi estabelecida para as análises dos peixes "in natura". Os peixes de tamanho pequeno foram destinados ao enlatamento, os médios à defumação e os grandes à salga e secagem.

Depois de separados por tamanho, foram pesados os lotes, cujas características são as seguintes:

\begin{tabular}{llll} 
& Pequenos & Médios & Grandes \\
\hline & \multicolumn{3}{c}{ (médias em gramas) } \\
\hline inteiros & 3.450 & 4.565 & 5.136 \\
s/ vísceras & 2.897 & 4.196 & $3.898(*)$ \\
& \multicolumn{4}{c}{} \\
resíduos & \multicolumn{4}{c}{ (médias em porcentagem) } \\
rendimento & 16,03 & 8,09 & $24,10(* *)$ \\
\hline
\end{tabular}

(*) e sem cabeças

$(* *)$ inclusive cabeças

\section{Defumação}

O processamento foi feito da seguinte maneira:

- pesagem dos lotes destinados ao processamento;

- lavagem dos peixes em água corrente, um a um, e colocados em escorredor;

- descamados e eviscerados sobre tábuas e com auxílio de facas;
- lavados em água corrente;

- colocados em salmoura a $25 \% \mathrm{p} / \mathrm{v}$ por $30 \mathrm{~min}$.;

- colocados em espeto de metal, pela cavidade ocular.

- levados ao secador de armário a $45^{\circ} \mathrm{C}$ por $30 \mathrm{~m}$;

- levados ao defumador.

Os peixes em seguida foram defumados utilizando serragem, constituída de diversas madeiras utilizadas rotineiramente em construções, durante 6 horas. A temperatura média da câmara foi de $100^{\circ} \mathrm{C}$. Os peixes defumados foram mantidos cerca de $24 \mathrm{~h}$, sob refrigeração, em refrigerador doméstico, para retiradas das amostras a serem submetidas às análises de composição centesimal e sensorial.

\section{Salga}

O processamento foi feito da seguinte maneira:

- pesagem dos lotes destinados ao processamento; - lavagem dos peixes em água corrente;

- colocados em tábuas, descamados, eviscerados e descabeçados com auxílio de faca;

- recortados em forma triangular sobre as tábuas; - aplicação do sal, utilizando $30 \%$ p/v (*);

- prensagem por cerca de 4 horas, utilizando tábuas sob e sobre os peixes;

- colocados em secador de armário, com circulação de ar aquecido, àté peso constante, a temperatura de $45^{\circ} \mathrm{C}$;

- mantidos ao ambiente por 6 meses.

o produto em seguida foi analisado quanto a sua composição centesimal.

\section{* Preparo do sal:}

- secou-se o sal grosso em estufa a $105^{\circ} \mathrm{C} \mathrm{p} / 30 \mathrm{~m}$; - moeu-se para obter menor granulação.

\section{Enlatamento}

O processamento foi feito da seguinte maneira:

- pesagem dos lotes destinados ao processamento;

- lavagem dos peixes em água corrente, um a um, e colocados em escorredor;

- descamados e eviscerados sobre tábuas e com auxílio de facas; 
- lavados em água corrente;

- colocados em salmoura a $25 \% \mathrm{p} / \mathrm{v}$, por $30 \mathrm{~min}$;

- lavados em água corrente;

- acomodados em escorredor;

- deixados sob vapor por $3 \mathrm{~min}$;

- feito acabamento, retirando-se a cabeça, nadadeiras e pele;

- acomodados nas latas de $\mathbf{4 0 0} \mathrm{ml}$ de capacidade, revestidas de verniz apropriado;

- os espaços foram preenchidos com óleo comestivel de soja até a borda das latas;

- exaustão em água à ebulição até atingir $70^{\circ} \mathrm{C}$ no interior da carne;

- recravadas as tampas;

- esterilizadas as latas em autoclave a $121^{\circ} \mathrm{C}$ por $60 \mathrm{~min}$;

- mantidas em armazenamento ao ambiente por 6 meses.

O produto em seguida foi analisado na sua composição centesimal e análise sensorial.

\section{Farinha de resíduos} maneira:

O processamento foi feito da seguinte

- pesagem do resíduo;

- colocados em secador de armário a $50^{\circ} \mathrm{C}$ até peso constante.

- moagem da massa seca em moinho de disco e transformação em farinha;

O produto foi analisado quanto à sua composição centesimal.

\section{Análises químicas}

Os peixes "in natura" (pequeno, médio, grande), defumados, salgados, enlatados e a farinha de resíduos foram analisados quanto aos teores de lipídeos, umidade, proteína e cinza.

Os peixes salgados, defumados e enlatados foram analisados quanto ao teor $\mathrm{de} \mathrm{NaCl}$.

Os métodos utilizados foram os seguintes:

\subsection{Umidade}

Determinada por método gravimétrico, através de perda de massa por aquecimento a $105^{\circ} \mathrm{C}$ até massa constante de acordo com LUDORFF (1963).

\subsection{Lipidios}

Determinados por método gravimétrico com aparelhamento Soxhlet de acordo com ASSOCIATIONOFOFFICIAL AGRICULTURAL CHEMIST (1971).

\subsection{Proteina}

Determinada pelo método micro-Kjeldhal, segundo a técnica descrita pela AOAC ASSOCIATIONOFOFFICIALAGRICULTURAL CHEMIST (1971).

\subsection{Cinza}

Determinada por método gravimétrico, através da perda de massa após incineração a $550^{\circ} \mathrm{C}$, segundo $A O A C$ - ASSOCIATION OF OFFICIAL AGRICULTURAL CHEMIST (1971).

\section{5. $\mathrm{NaCl}$}

Calculado o teor percentual de Cloreto de Sódio por diferença de peso entre os valores de cinza antes e após a salmouragem ou a salga, utilizando-se os dados correspondentes a cada lote destinado ao seu processamento.

\subsection{Preparo do material para análise}

Os peixes "in natura" (pequeno, médio e grande) após retirada da parte não comestível, foram homogeneizados em liquidificador a $\mathbf{2 . 0 0 0}$ rpm por 2 minutos. Nos defumados e nos salgados secos foi utilizada a parte comestível homogeneizada.

No caso dos peixes enlatados, estes foram retirados da lata, colocados sobre papel de filtro para que este absorvesse o excesso do bleo de enlatamento $e$ homogeneizados. $\mathrm{Na}$ farinha, utilizou-se o produto diretamente.

\section{Análise sensorial}

Foram aplicados os testes de preferência e adaptados de KRAMER \& TWGG (1970) para julgar cinco características: aparência, cor, aroma, sabor e textura em quatro categorias: ótimo, bom, razoável e não aceitável para as conservas de peixes defumados e enlatados. 
TABELA 1 - Composição centesimal do pacu "in natura"

\begin{tabular}{ccccc}
\hline \hline (Lotes) & $\begin{array}{c}\text { Umidade } \\
(\mathrm{g} / 100 \mathrm{~g})\end{array}$ & $\begin{array}{c}\text { Proteína } \\
(\mathrm{g} / 100 \mathrm{~g})\end{array}$ & $\begin{array}{c}\text { Lipídeos } \\
(\mathrm{g} / 100 \mathrm{~g})\end{array}$ & $\begin{array}{c}\text { Cinza } \\
(\mathrm{g} / 100 \mathrm{~g})\end{array}$ \\
\hline Pequeno & 75,54 & 19,80 & 3,33 & 1,96 \\
Médio & 76,54 & 18,99 & 2,25 & 1,99 \\
Grande & 74,54 & 18,27 & 5,79 & 1,51 \\
\hline Médias & 75,54 & 19,02 & 3,79 & 1,82 \\
\hline \hline
\end{tabular}

TABELA 2 - Composição centesimal do pacu processado

\begin{tabular}{lccccc}
\hline \hline Conservas) & $\begin{array}{c}\text { Umidade } \\
(\mathrm{g} / 100 \mathrm{~g})\end{array}$ & $\begin{array}{c}\text { Proteína } \\
(\mathrm{g} / 100 \mathrm{~g})\end{array}$ & $\begin{array}{c}\text { Lipídeos } \\
(\mathrm{g} / 100 \mathrm{~g})\end{array}$ & $\begin{array}{c}\text { Cinza } \\
(\mathrm{g} / 100 \mathrm{~g})\end{array}$ & $\begin{array}{c}\mathrm{NaCl} \\
(\mathrm{g} / 100 \mathrm{~g})\end{array}$ \\
\hline Salgado-seco & 11,36 & 52,53 & 18,31 & 17,76 & 16,25 \\
Defumado & 70,25 & 23,80 & 2,69 & 3,13 & 1,17 \\
Enlatado & 62,19 & 18,59 & 14,34 & 2,79 & 1,29 \\
$\begin{array}{l}\text { Farinha } \\
\text { (resíduos) }\end{array}$ & 15,73 & 42,94 & 20,91 & 20,42 & - \\
\hline \hline
\end{tabular}

TABELA 3 - Análise sensorial do pacu enlatado (\%)

\begin{tabular}{lcccc}
\hline \hline \multicolumn{1}{c}{ Atributos } & Ótimo & Bom & Regular & Não aceitável \\
\hline Aparência na lata & 89 & 11 & - & - \\
Aparência no prato & 56 & 44 & - & - \\
Aroma & 67 & 33 & - & - \\
Sabor & 56 & 33 & 11 & - \\
Textura & 22 & 56 & 22 & - \\
\hline \hline
\end{tabular}

TABELA 4 - Análise sensorial do pacu defumado (\%)

\begin{tabular}{lcccc}
\hline \hline Atributos & Ótimo & Bom & Regular & Não aceitável \\
\hline Aparência & 45 & 55 & - & - \\
Aroma & 35 & 60 & 5 & - \\
Sabor & 25 & 55 & 20 & - \\
Textura & 50 & 50 & - & - \\
\hline \hline
\end{tabular}

Sci. agric., Piracicaba,SP. 50(2):303-310, jun./set. 1993 
Pela TABELA 1 podemos notar o alto teor de umidade do pescado "in natura", que além de outros fatores, faz com que este seja um alimento bastante perecível.

Os teores dos componentes da composição centesimal do pacu, conforme apresentado na TABELA 1, estão de acôrdo com as faixas de variação citadas por NATARAJAN \& SREENIVASA (1961).

\section{RESULTADOS E DISCUSSÃO}

O pacu pode ser considerado um peixe de médio teor de lipídeos. O teor de gordura é determinante para a escolha do processamento do pescado, conforme discutido por FERREIRA (1987).

O teor de lipídeos se muito elevado limitará a salga pois o sal potencia a oxidação lipídica, por outro lado os lipídeos tem que estar presentes na carne, pois são lubrificantes importantes durante a defumação para que o produto não fique ressecado com a passagem da fumaça.

O teor de $2,25 \%$ de lipídeos na carne dos pacus de tamanho médio destinados à defumaçâo, não é baixo o suficiente para prejudicar o produto defumado; já o teor de $5,79 \%$ dos pacus maiores destinados à salga não é alto para impedir o emprego deste processo.

$O$ teor de gordura do produto final, $18,31 \%$, conforme a TABELA 2 , é elevado,sendo portanto conveniente recomendar-se o uso de antioxidantes ou o armazenamento refrigerado, conforme discutido por BERGER et al. (1968).

O mesmo pode-se dizer da farinha, que apresenta elevado teor de lipídeos, $20,91 \%$. Neste caso,as recomendações de alterações no preparo precisam provir de novas pesquisas, para não haver encarecimento do produto, uma vez que o próprio aproveitamento de um material residual não justificaria custos adicionais de produção.

Ainda na TABELA 2, o alto teor de $\mathrm{NaCl}$ do peixe salgado seco, $16,25 \%$, se deve a salga necessária para a conservação pela diminuição da atividade de água (aw).

O pescado defumado apresenta teor elevado de umidade pois o princípio de conservação não é o da diminuição da aw, e sim o efeito das propriedades bactericidas existentes na fumaça. O produto praticamente conserva as mesmas características do pescado "in natura". O pescado defumado tem $70,25 \%$ de umidade, valor similar ao citado por LUDORFF (1963).
Para o enlatado, o valor do teor de lipídios -obtido, $14,34 \%$ é influenciado pela absorção do óleo comestível utilizado no acondicionamento para enlatamento.

Já no caso da farinha de resíduos, o teor de cinza é alto, $20,42 \%$, pois foi utilizada a parte óssea do peixe, constituindo-se um produto mais rico em minerais.

As TABELAS 3 e 4 mostram que esses produtos possuem boa aceitação, não havendo

nenhum caso de "não aceitação" por parte dos degustadores.

Os pacus se prestam ao enlatamento pois foi possível obter-se $67 \%$ de aceitação por parte dos degustadores para aroma e $56 \%$ de aceitação para sabor, na categoria ótimo, conforme os resultados da TABELA 3.

A boa aceitação dos peixes defumados, vista na TABELA 4, 50\% e 50\% de ótimo e bom para textura, $60 \%$ de bom para aroma e $55 \%$ de bom para sabor, confirmam a opinião de BORGSTROM (1961), sobre a importância da defumação nas características sensoriais.

\section{CONCLUSÃO}

O trabalho mostra que o peścado de água doce, como é o caso do pacu, é viável aos processos tecnológicos de baixo investimento (salga e defumação) bem como no de enlatamento.

Particularmente, os peixes utilizados neste trabalho, criados pela Prefeitura Municipal de Piracicaba, poderão ser destinados à utilização em forma de salgados secos, defumados e enlatados para a merenda escolar do município. Chegou-se, portanto,a novas opções de consumo e à possibilidade de mais frequência do uso do pescado nas refeições das escolas, do que se apenas utilizado na forma "in natura".

\section{REFERÊNCIAS BIBLIOGRÁFICAS}

ANDRADE, M.O. de; LIMA, U. de A. Contribuição ao conhecimento do valor nutritivo do peixe de água doce, Pimelodus clarias Bloch (Mandi). Anais da Escola Superior de Agricultura "Luiz de Queiroz", Piracicaba, v.52, p.563-666, 1975.

ANDRADE, M.O. de; LIMA, U, de A. Variação estacional da composição centesimal do peixe de água doce Pimelodus clarias Bloch (Mandi). Anais da Escola Superior de Agricultura "Luiz de Queiroz", Piracicaba, v.52, p.575-580, 1975. 
ANDRADE, M.O. de; LMA, U. de A. Agroindústria de alimentos - Produção de pescado defumado. $\mathbf{O}$ Solo, Piracicaba, v.75, n.1, p.16-29, 1983.

ASSOCIATION OF OFFICIAL AGRICULTURAL CHEMIST. Official and tentative methods of analysis. 11 ed. Washington: AOAC, 1971, p.295, 526 e 858.

BERGER, J.; GROTH, E.; VERRONE, N.V.M.A. ; GALLO, V. Proteina concentrada de peixe (FPC): pré-projeto. São Paulo. Comissão Interestadual da Bacia Paraná-Uruguai, 1968. 99p.

Bonetto, A.A.; CAstello, H.P. Pesca y piscicultura em aguas continentales de América Latina. Washington, D.C.: OEA, 1985. 118 p.

BORGSTROM, G. Fish as food. New York: Academic Press, 1961, v.4, 118p.

CAPONT, F.L. Introdução à tecnologia de pescados Santos: ITAL/OEA, 1971, 50p.

FERREIRA, S.O. Aplicação de tecnologia a espécies de pescado de água doce visando atender a agroindústria rural. Piracicaba, 1987, 121p. Dissertação (Mestrado) - Escola Superior de Agricultura "Luiz de Queiroz", Universidade de São Paulo.

FERREIRA, S.O.; ANDRADE, M.O. de. Agroindustria de pescado (salga, defumação e anchovagem), Piracicaba: ESALQ, 1990, 24 p. (ESALQ, Informativo Técnico, 6).

GEIGER, E. Fish protein - nutritive aspects. In: BORGSTROM, G. Fish as food. New York, Academic Press, 1962. cap.2, p.32-38.

GEROMEL, E.J.; FORSTER, R.J. Principios fundamentais em tecnologia de pescados. São Paulo: Fundação Tropical de Pesquisas e Tecnologia . 1982. 127p.

GRECCHI, D. Salga de peixes. Revista Nacional da Pesca. Santos, v.14, n.120, p.10-13, 1979.

HERSON, A.C.; HULlAND, E.D. Control de los microrganismos que alteran los alimentos. In: Conservas alimenticeas: fundamentos tecnicomicrobiologicos. Zaragoza: Acribia, 1974. cap. 3, p.48-50,60-61.
KRAMER, A.; TWIGG, B.A. Fundamentals of quality control for the food industry. Westport: AVI, 1970, v.1, $577 \mathrm{p}$.

LANTZ, A.W. Produits speciaux des poissons d'ean douce. Office des Recherches sur les Pecheries du Canada. 1969. p.

LUDORFF, W. E pescado y sus productos. Zaragoza: Acribia, 1963, 304p.

MACHADO, Z.L.; GURGEL, J.J.S. Sobre a salga e a secagem da traira (Hoplias malabaricus) e pescada do Piaui (Plagioscion squamosissimus). Boletim de Estudos de Pesca. Recife, v.5, n.1, p.31-41, 1965.

MAGALHĀES, E. A defumaçāo do pescado. Rio de Janeiro, Ministério da Agricultura, 1961, 31 p.

MEIZIES, A.; REICHWALD, I. Lipids in the muscle and roe of fresh and smoked fish. Zeitschrift fur Emaehrungswissenschaft, Muenster, v.12, n.4, p.248-251, 1973

MOORJANI, M.N.; LAHIRY, N.L.; NAIR, R.B.; UPADHYE, A.N.; RAO, S.V. Nutritional value of fish flour I: effect of storage of sardine meal prior to its extraction with ethanol. Food Technology. Champaign, v.19, n.2, p.212-215, 1965.

NATARAJAN, U.M.; SREenivasa, A. Proximate and mineral composition of freshwater fishes. Indian Journal of Fisheries. Bhavanisagar, v.8, n.2, p.422$429,1961$.

NOMURA, H. Aquicultura e biologia dos peixes. São Paulo: Brasil, 1978. 200p.

SALES, R. de O.; MONTEIRO, J.C.S.; MARTINS, C.B.; MAIA, G.A.; MACHADO, N.A.N.; FEITOSA, T. Estudo da estabilidade da Tilápia do Nilo (Sarotherodon niloticus) defumada. Ciència Agronomica, Fortaleza, v.19, n.2, p.65-69, 1988.

SHEVCHENKO, M.G.; LAPSHIN, I.I. Effect of the method of smoking of large-fish fillet products on the resistance of their lipids to oxidate decomposition. Rybno Khozyaistvo, Moscou. v.11, p.74-77, 1975.

Trabalho enviado para publicação em 23.06.92

Trabalho aceito para publicação em 11.11 .92 